\title{
Multichannel Singular Spectrum Analysis in the Estimates of Common Environmental Effects Affecting GPS Observations
}

\author{
Marta Gruszczynska, ${ }^{1}$ (D) Severine Rosat, ${ }^{2}$ Anna Klos, ${ }^{1}$ Maciej Gruszczynski, ${ }^{1}$ and Janusz Bogusz ${ }^{1}$
}

\begin{abstract}
We described a spatio-temporal analysis of environmental loading models: atmospheric, continental hydrology, and non-tidal ocean changes, based on multichannel singular spectrum analysis (MSSA). We extracted the common annual signal for 16 different sections related to climate zones: equatorial, arid, warm, snow, polar and continents. We used the loading models estimated for a set of 229 ITRF2014 (International Terrestrial Reference Frame) International GNSS Service (IGS) stations and discussed the amount of variance explained by individual modes, proving that the common annual signal accounts for 16,24 and $68 \%$ of the total variance of non-tidal ocean, atmospheric and hydrological loading models, respectively. Having removed the common environmental MSSA seasonal curve from the corresponding GPS position time series, we found that the residual station-specific annual curve modelled with the least-squares estimation has the amplitude of maximum $2 \mathrm{~mm}$. This means that the environmental loading models underestimate the seasonalities observed by the GPS system. The remaining signal present in the seasonal frequency band arises from the systematic errors which are not of common environmental or geophysical origin. Using common mode error (CME) estimates, we showed that the direct removal of environmental loading models from the GPS series causes an artificial loss in the CME power spectra between 10 and 80 cycles per year. When environmental effect is removed from GPS series with MSSA curves, no influence on the character of spectra of CME estimates was noticed.
\end{abstract}

Key words: Multichannel singular spectrum analysis, seasonal signals, GPS, environmental loading models.

Electronic supplementary material The online version of this article (https://doi.org/10.1007/s00024-018-1814-0) contains supplementary material, which is available to authorized users.

1 Faculty of Civil Engineering and Geodesy, Military University of Technology, Warsaw, Poland. E-mail: marta.gruszczynska@wat.edu.pl

2 Institut de Physique du Globe de Strasbourg, UMR 7516, Université de Strasbourg/EOST, CNRS, Strasbourg, France.

\section{Introduction}

Seasonal changes are a component part of the Global Positioning System (GPS) position time series, especially the vertical direction (Blewitt and Lavallée 2002; Collilieux et al. 2007). In most cases, those variations result from real geophysical phenomena which deform the Earth's surface. They are broadly explained and modelled by environmental loading effects (van Dam and Wahr 1998; Jiang et al. 2013). Atmospheric (van Dam and Wahr 1987), hydrological (van Dam et al. 2001) and non-tidal ocean (van Dam et al. 2012) loadings are the most important contributors of seasonal variations to many GPS stations in different parts of the world. The appropriate models can be removed directly from the GPS position time series to reduce the influence they might have on the observed displacements. This approach has proved to decrease the root mean square (RMS) of the GPS position time series (Jiang et al. 2013). However, according to Santamaría-Gomez and Mémin (2015), such an approach reduces only the amplitude of white noise of the GPS position time series. Klos et al. (2017) showed that the direct removal of environmental loading models from the GPS observations causes the evident change in the power spectrum density of noise for frequencies between 4 and 80 cycles per year (cpy).

Beyond real geophysical origins, seasonal changes in the GPS position time series can be also generated by systematic errors (Ray et al. 2008) or by spurious effects (Penna et al. 2007). Both can influence permanent stations individually or be similar for stations situated not far from each other.

As shown by Dong et al. (2002), both the GPS position time series and the environmental loading 
models contain the common seasonal signal which characterizes the data from a certain region of the world. Freymueller (2009), Tesmer et al. (2009) and Bogusz et al. (2015a) proposed to employ stacking and clustering methods to estimate regional mean annual oscillations from the time series and to group them from a regional signal. They all proved that the neighbouring stations are characterized by a similar seasonal signal.

Few methods such as Singular Spectrum Analysis (SSA), Wavelet Decomposition (WD) and Kalman Filter $(\mathrm{KF})$ have been already used to retrieve stationdependent time-varying curves from the GPS position time series (Chen et al. 2013; Gruszczynska et al. 2016; Didova et al. 2016; Klos et al. 2018a). However, neither of them is able to separate real and spurious effects from the GPS data. Lately, multichannel singular spectrum analysis (MSSA) was proposed by Walwer et al. (2016) for stations situated close to each other. They demonstrated that MSSA is able to model the common seasonal signal in the GPS position time series. Zhu et al. (2016) used the MSSA approach to investigate the inter-annual oscillations in glacier mass change estimated from gravity recovery and climate experiment (GRACE) data in Central Asia. Gruszczynska et al. (2017) compared the MSSA-, SSA- and least-squares estimationderived seasonal signals. They showed that the seasonal signals detected by MSSA are not affected by noise as much as the SSA-derived oscillations. It was explained by the fact that SSA estimates individually fitted curve for the analysed station, while MSSA takes into account the common effects which are observed by few neighbouring GPS stations. As the noise is mainly a station-specific signal, MSSA curves will not be affected by it as much as SSA curves.

To indicate the signals which arise from real geophysical effects, Klos et al. (2017) proposed a two-stage solution based on Improved Singular Spectrum Analysis (ISSA, Shen et al. 2015). When applied for loading models from an individual station, the time-varying seasonal signals from environmental atmospheric, hydrological and non-tidal ocean loadings were extracted, causing the character of the stochastic part characterized a power-law noise (e.g. Williams 2003; Bogusz and Kontny 2011;
Santamaría-Gomez et al. 2011; Klos et al. 2016; Klos and Bogusz 2017) remained intact. In this research, we assumed that the GPS position time series should not be affected by the high frequency part of environmental loadings series as we did not know if GPS observations to a large extent are influenced by the environmental effects. Therefore, we focused on the common environmental effect in a form of timevarying annual curve which is observed at the GPS permanent stations and proposed its modelling without any alteration in the character of the stochastic part of the time series.

Beyond seasonal signals, the GPS-derived series are also characterized by common mode error (CME), being a sum of the systematic errors (Wdowinski et al. 1997; Nikolaidis 2002; King et al. 2010). Mismodeling of the earth orientation parameters (EOPs), mis- or un-modelled large-scale atmospheric and hydrologic effects or small scale crust deformations, all increase spatial correlations between individual series. CME can be easily estimated using stacking (Wdowinski et al. 1997; Nikolaidis 2002), spatial filtering (Márquez-Azúa and DeMets 2003) or orthogonal transformation functions. The latter is considered to be the most effective in reflecting the real nature of CME (Dong et al. 2006). Yuan et al. (2008) proved that a direct removal of surface mass loadings can significantly reduce the power-law noise. However, they did not investigate to what extent the properties of CME are affected. As was shown by Klos et al. (2017) a part of the power is removed when real geophysical effects are considered by direct subtraction of environmental loading models. We presumed that the CME values may also be affected by such removal.

In this paper, we proposed the spatial analysis of environmental loading models based on MSSA to extract the common annual signal for 16 different sections related to the climate zones (i.e. equatorial, arid, warm, snow, polar) and continents. We then modelled with MSSA the time-varying seasonal signal from environmental loading models and subtracted them from the GPS height time series. This was aimed to remove real geophysical changes from the GPS data leaving the noise character of time series unchanged. The benefits of this approach were presented for CME estimates which should not 
include the environmental effects, as they were removed by the MSSA approach and, most importantly, no influence on CME character should be noticed.

\section{Methodology}

In this section, we provided a detailed description of the data and the methodology we used. Data included the environmental loading models and the GPS height time series collected at 229 stations from around the globe. The division into 16 different sections according to the climate classification is also presented.

\subsection{Data}

We employed the GPS position time series from 229 stations distributed globally (Fig. 1). Daily time series were derived from network solution
(Rebischung et al. 2016) produced by the International GNSS Service (IGS). They contributed to the latest realization of the International Terrestrial Reference System (namely ITRF2014; Altamimi et al. 2016). We selected the vertical components which were not shorter than 10 years. To remove offsets, we used the epochs defined by IGS in station $\log$-files with the manual inspection of the series. Outliers were removed with the Interquartile Range (IQR) approach.

Under the Synthesis Report about Climate Change published by Intergovernmental Panel on Climate Change (IPCC), a region's climate is generated by the system, which has five main components: atmosphere, hydrosphere, cryosphere, lithosphere, and biosphere (AR4 SYR Synthesis Report Annexes, http://www.ipcc.ch, retrieved on 2017-06-28). According to this report, we investigated environmental loading effects which may be correlated within climate zones. Therefore, 229 stations were divided into sixteen sections (Table 1, and Table S1

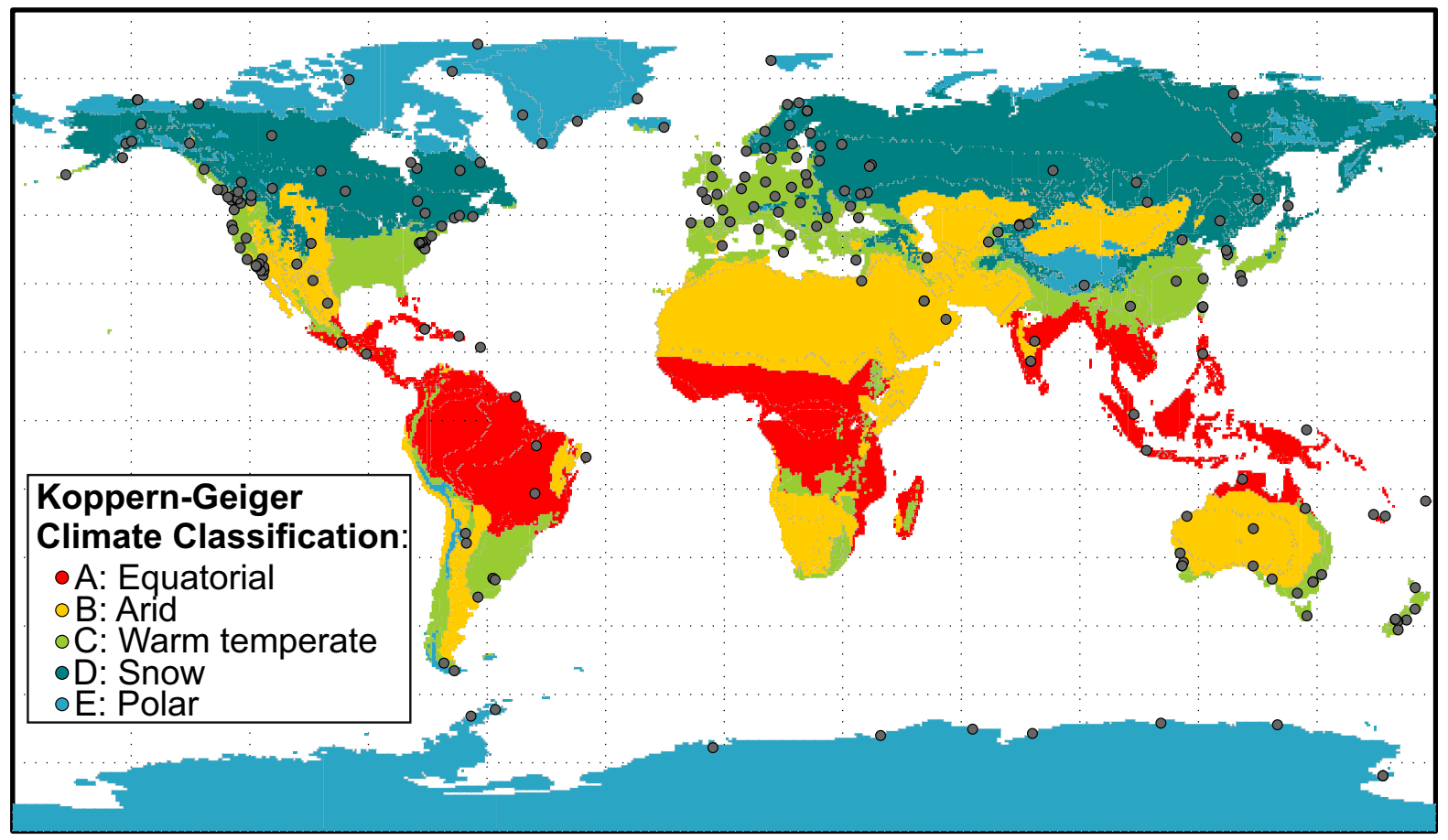

Figure 1

World Map of Köppen-Geiger Climate Classification with the GPS permanent stations considered in this analysis plotted in grey. The A: Equatorial, B: Arid, C: Warm temperate, D: Snow and E: Polar climate zones are presented in red, yellow, green, turquoise and blue, respectively 
Table 1

Number of stations included in a particular section, i.e. a part of continent that is assigned by climate zone

\begin{tabular}{lllr}
\hline Number of section & Climate zone & Continent & Number of stations \\
\hline 1 & A: Equatorial & Asia & 6 \\
2 & & Australia & 6 \\
3 & B: Arid & South America & 7 \\
4 & & Asia & 6 \\
5 & & Australia & 3 \\
6 & C: Warm & North America & 13 \\
7 & & Asia & 11 \\
8 & & Australia & 24 \\
9 & & Europe & 30 \\
10 & & North America & 33 \\
11 & D: Snow & South America & 6 \\
12 & & Asia & 17 \\
13 & & Europe & 18 \\
14 & E: Polar & North America & 25 \\
16 & & Antarctica & 13 \\
\hline
\end{tabular}

The full list of stations is available in Table S1 in Supplementary materials. The symbols and names of the sections are used throughout the entire paper, as, e.g. A: Equatorial Asia or D: Snow Europe

in Supplementary Materials) which are associated with these zones and also with different continents. We used the Köppen-Geiger Climate Classification (Rubel and Kottek 2010) to divide stations according to similar conditions. Then, the time-varying curves were modelled separately for each section.

The atmospheric, hydrological and non-tidal ocean loading models in Centre-of-Figure (CF) frame were employed. Atmospheric loadings were determined from ERA interim (ECMWF Reanalysis) model (Dee et al. 2011). Non-tidal ocean loadings were estimated from Estimation of the Circulation and Climate of the Ocean version 2 (ECCO2) (Menemenlis et al. 2008) ocean bottom pressure model. Hydrological loading (soil moisture and snow) was estimated from modern era-retrospective analysis (MERRA) land model (Reichle et al. 2011). These environmental loadings were developed at the Ecole et Observatoire des Sciences de la Terre (EOST) loading service available at http:// loading.u-strasbg.fr/.

Since the ECCO2 model and the GPS position time series are sampled every day, the ERAIN and MERRA models were decimated into a daily sampling using a low-pass filter. One of the requirements of the MSSA approach is a common time span of data sets; therefore, we selected a period from 1st January 1994 to 14th February 2015 to be common for all stations. In this
Figure 2

The selected environmental loading models presented for various sections considered in this research. ERAIN, MERRA and ECCO2 models are shown in blue, brown and violet, respectively. A clear time variability in each series may be observed. Obviously, the spread and amplitudes of ERAIN, MERRA and ECCO2 curves depend on the sections which are considered

study, we focused on the vertical component for which the environmental loading is the most significant (Dach et al. 2011; van Dam et al. 2012).

Figure 2 presents series of environmental loadings for selected stations from each section to show the time variability we may be dealing with. Depending on the section considered, the atmospheric, hydrological and non-tidal ocean effects can be larger than others. According to BAKO (Cibinong, Indonesia), ALIC (Alice Springs, Australia), BREW (Brewster, United States) and TUCU (San Miguel de Tucuman, Argentina) stations, we may notice that the amplitude of MERRA model significantly varies over time with maximum peak-to-peak amplitude being equal to about 5, 7, 10 and $4 \mathrm{~mm}$, respectively. Similarly, we may see in atmospheric loading at ACOR (A Coruna, Spain) and SEAT (Seattle, United States) stations that the peaks differ by 5 and $4 \mathrm{~mm}$, respectively. DARW (Darwin, Australia) station is characterized by ECCO2 model with time-varying amplitude of about $2 \mathrm{~mm}$. 

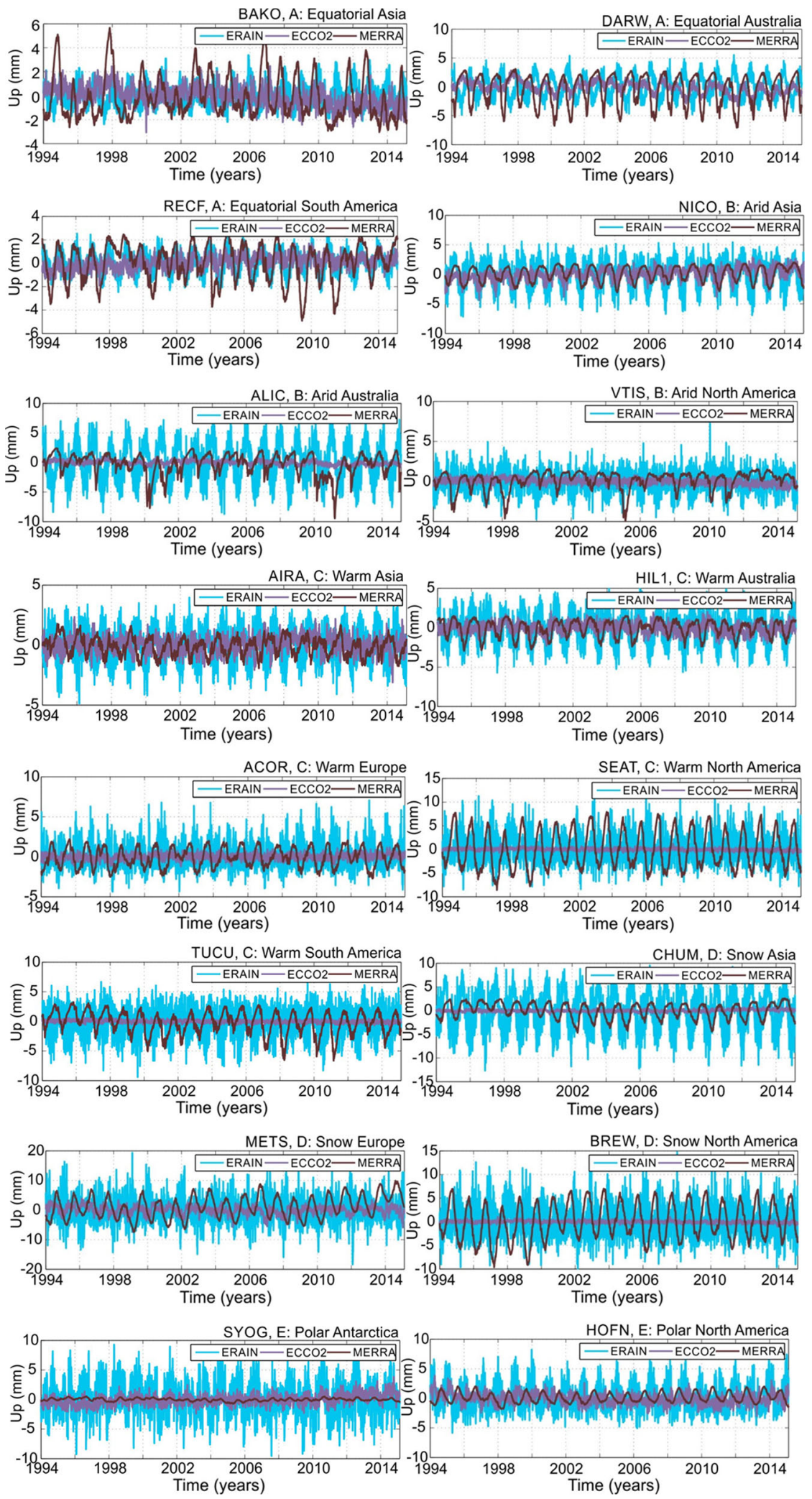


\subsection{Multichannel Singular Spectrum Analysis (MSSA)}

Multichannel (or multivariate) singular spectrum analysis (MSSA) is a method that allows analysing spatial and temporal correlations between different time series (Broomhead and King 1986a, b; Allen and Robertson 1996; Ghil et al. 2002). The common modes of spatio-temporal variability of a set of time series are described by empirical basic functions. MSSA, similarly to its univariate equivalent method named SSA, consists of two stages: decomposition of the grand-covariance matrix and reconstruction of interesting component. Trend, seasonalities, and noise common for all series are computed in the undermentioned steps:

Step 1. Application of the Embedding Procedure to Estimate the Full Augmented Trajectory Matrix. Firstly, the sliding window of $M$-length which will be moved across the entire dataset has to be chosen. To determine annual signals we focused on 3-, 4- and 6-year sliding windows, depending on the series. In the embedding procedure, a trajectory matrix was computed (Eq. 1). Each row relates to observations which were included in the sliding window of size $M$. This window is shifted until the last observation $N$ is reached. This trajectory matrix has a dimension of $N^{\prime} \times M$, where $N^{\prime}=N-M+1$ (Broomhead and King 1986a, b; Allen and Robertson 1996; Ghil et al. 2002):

$$
\tilde{X}_{l}=\left(\begin{array}{cccc}
X_{l}(1) & X_{l}(2) & \cdots & X_{l}(M) \\
X_{l}(2) & X_{l}(3) & \cdots & X_{l}(M+1) \\
\vdots & \vdots & \cdots & \vdots \\
X_{l}\left(N^{\prime}-1\right) & \vdots & \cdots & X_{l}(N-1) \\
X_{l}\left(N^{\prime}\right) & X_{l}\left(N^{\prime}+1\right) & \cdots & X_{l}(N)
\end{array}\right) .
$$

Then, the multichannel trajectory matrix $\tilde{\mathbf{D}}$ is estimated as:

$$
\tilde{\mathbf{D}}=\left(\tilde{\mathbf{X}}_{1}, \tilde{\mathbf{X}}_{2}, \ldots, \tilde{\mathbf{X}}_{L}\right)
$$

where $L$ is the number of time series included in the analysed dataset. In our research, $L$ was equal to 229 (total number of stations).

Step 2. Estimation of the Grand Lag-Covariance. The grand lag-covariance matrix is defined as:

$$
\tilde{\mathbf{C}}_{D}=\frac{1}{N^{\prime}} \tilde{\mathbf{D}}^{t} \tilde{\mathbf{D}}
$$

and was computed in this research using the BK algorithm (Broomhead and King 1986b).

Step 3. Decomposition of Grand Lag-Covariance Matrix to Determine Eigenvalues and Eigenvectors. The grand lag-covariance matrix is diagonalized using singular value decomposition (SVD) in order to compute eigenvalues $\lambda_{k}$ and eigenvectors $\mathbf{E}^{k}$ also known as empirical orthogonal functions (EOFs).

Step 4. Determination of $k$-th Principal Component (PC) as Single-Channel Time Series. The consecutive PCs $A^{k}$ are computed with the eigenvectors estimated in step 3:

$$
A^{k}(t)=\sum_{j=1}^{M} \sum_{l=1}^{L} X_{l}(t+j-1) E_{l}^{k}(j) .
$$

The frequency of a particular PC is determined using a periodogram. Any two PCs relating to the same frequency as well as the eigenvectors which correspond to those PCs are in quadrature.

Step 5. Computation of the Reconstructed Components $(R C)$ of Frequency of Interest. The $k$-th $\mathrm{RC}$ at time $t$ for time series $l$ is defined as (Plaut and Vautard 1994):

$$
R_{l}^{k}(t)=\left\{\begin{array}{ccc}
\frac{1}{M} \sum_{j=1}^{M} A^{k}(t-j+1) E_{l}^{k}(j) & \text { for } & M \leq t \leq N-M+1 \\
\frac{1}{i} \sum_{j=1}^{M} A^{k}(t-j+1) E_{l}^{k}(j) & \text { for } & 1 \leq t<M-1 \\
\frac{1}{N-i+1} \sum_{j=1-N+M}^{M} A^{k}(t-j+1) E_{l}^{k}(j) & \text { for } & N-M+2 \leq t \leq N
\end{array} .\right.
$$

Depending on the frequency which interests us, various components can be reconstructed. It is worth emphasizing that summing all RCs, the original time series is reconstructed with no loss in information.

\section{Results}

In the following section, we presented the results of research on time-varying seasonal signals 
estimated with MSSA, separately for environmental loadings in each considered section. Then, we analysed the residuals of the GPS height time series obtained by subtraction of the common time-varying annual curves from data. Finally, we estimated the CME values to decide on the efficiency of the proposed approach. We aimed to propose MSSA as an alternative method to remove the common environmental effect from the GPS position time series without affecting their stochastic characters.

\subsection{Common Seasonal Signals Estimated from Environmental Loadings}

Common seasonal signals were estimated with MSSA from environmental loadings separately for sixteen considered sections (Fig. 3) and then summed to each other for the time span of 1.01.199414.02.2015. Residuals of the GPS height time series were produced by de-trending each of them and by removing the common annual signal for epochs corresponding to GPS observations. These residuals were then subjected to CME estimates. In this research, we intentionally focused on annual period, as the percentage of total variance of time series explained by modes of annual signal is much higher than the variance explained by any other pair of modes (Gruszczynska et al. 2016).

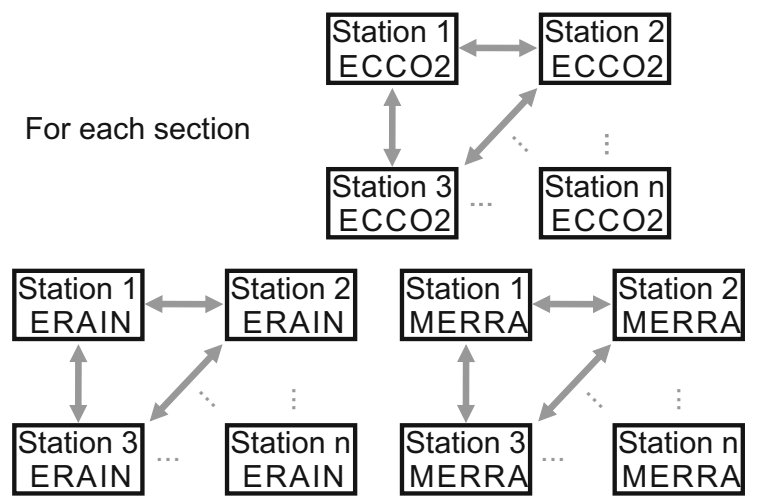

Figure 3

An idea of MSSA employed for a particular section and environmental model. The common annual signal was estimated based on time series included in the considered section, separately either for each section or each loading model. Then, the common annual signals estimated for ERAIN, MERRA and ECCO2 were summed to each other to reveal the common environmental effect which affects the GPS position time series
The principal components which correspond to the same frequency describe the common character of the employed time series. In other words, each individual PC constitutes a pattern of the common signal. PCs and eigenvectors of the annual period were combined to estimate the $k$-th $\mathrm{RC}$ to determine common oscillations for stations in a particular section, not of the individual station. The percentage of variance explained by the common signal is strictly related to the variance of entire time series estimated including trend, noise and other seasonal signals. It can be only interpreted in the context of all the time series common components variability. As an example, we can provide a series with the significant amplitude of the common annual signal, and the common trend, noise, and other seasonalities being also significant. Then, the contribution of the common annual signal is comparatively low in relation to the remaining components identified through the MSSA procedure. On the contrary, if the variance of trend, noise and other seasonalities is small, the total variance of data explained by the annual curve will be significant and large.,

From Fig. 4, we can notice that for ERAIN loading model, two first PCs are always related to common annual signals explaining between 4 and $80 \%$ of the total variance of data. If the percentage of variance explained by the annual signal is relatively low, the higher is the variance that represents the sum of the other time series components (trend, noise, and other seasonalities). For 7 sections, i.e. B: Arid North America, C: Warm Europe, C: Warm North and South America, D: Snow Europe, D: Snow North America and E: Polar Antarctica, the variance explained by the annual signal is relatively low in comparison to the variance explained by other modes and varies between 4 and $8 \%$. For other sections, this variance is much higher and ranges $31-80 \%$.

For MERRA loading model, the two first PCs always combine to annual signal. The variance explained by it varies between 31 and $83 \%$ of total variance of data. Zones as B: Arid Australia, B: Arid North America and C: Warm Australia are characterized by a high contribution of lower modes into the total percentage of variance equal to nearly $70 \%$ at maximum. For other sections, this percentage 


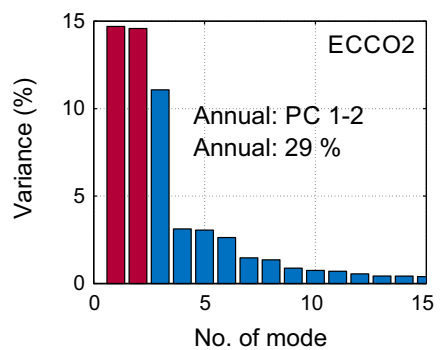

No. of mode
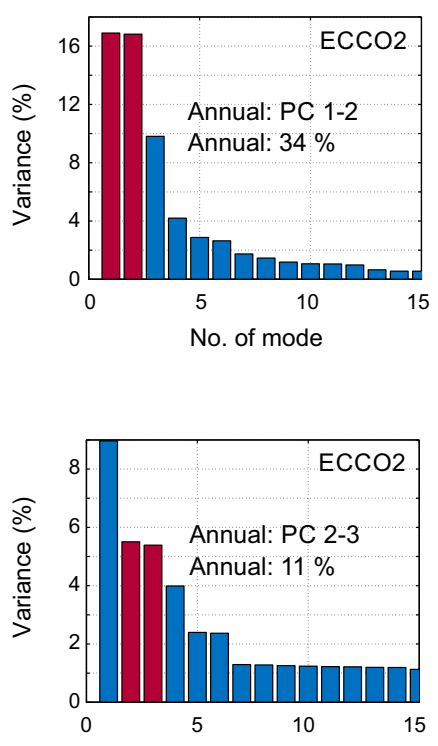

No. of mode

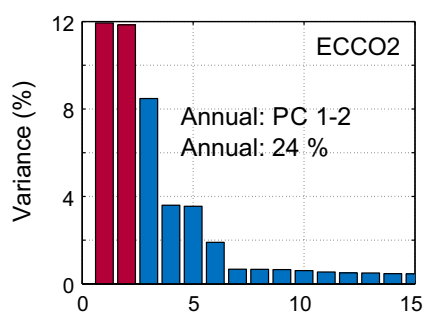

No. of mode

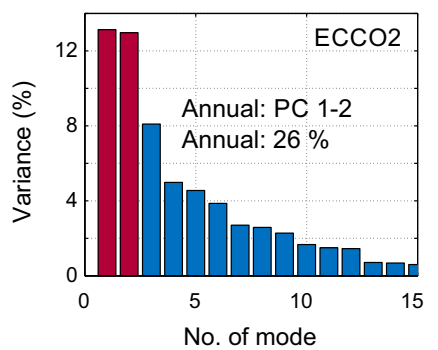

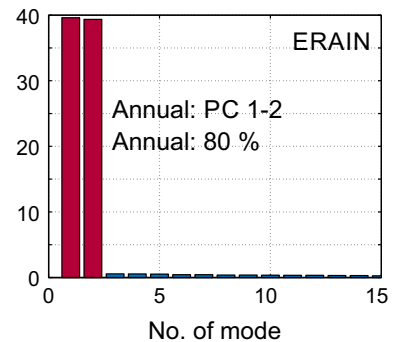
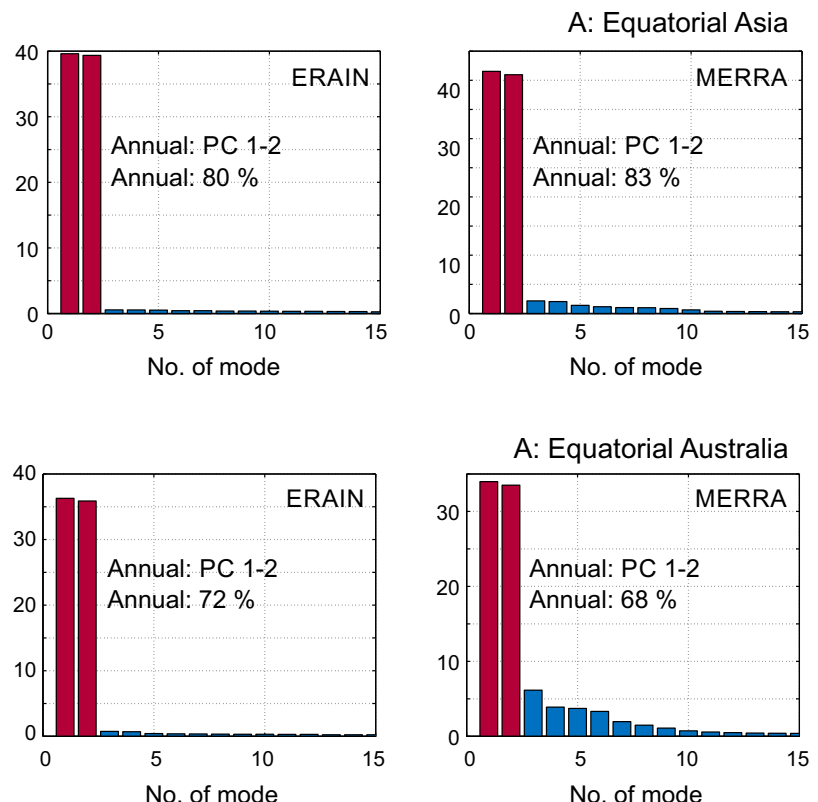

A: Equatorial Australia

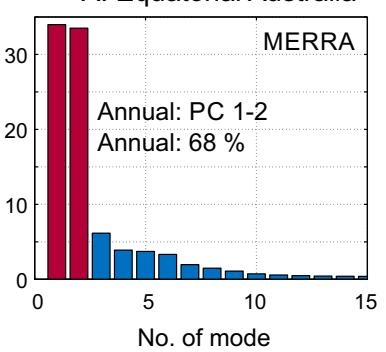

A: Equatorial South America
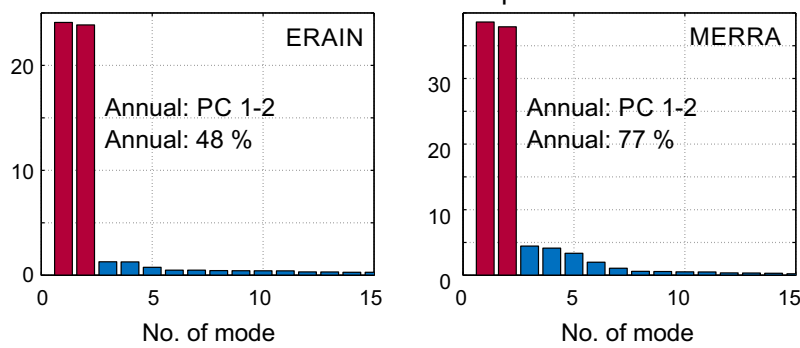

No. of mode

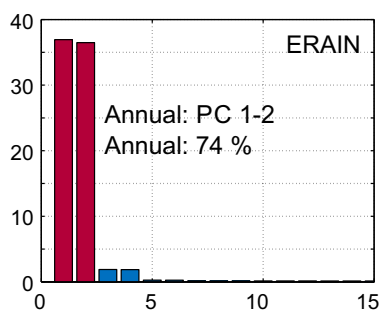

No. of mode

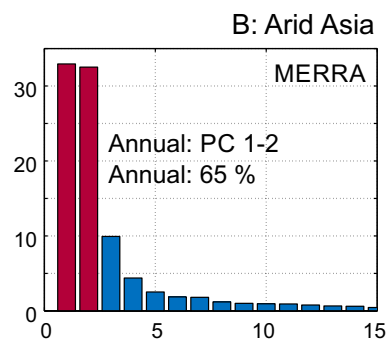

No. of mode

B: Arid Australia
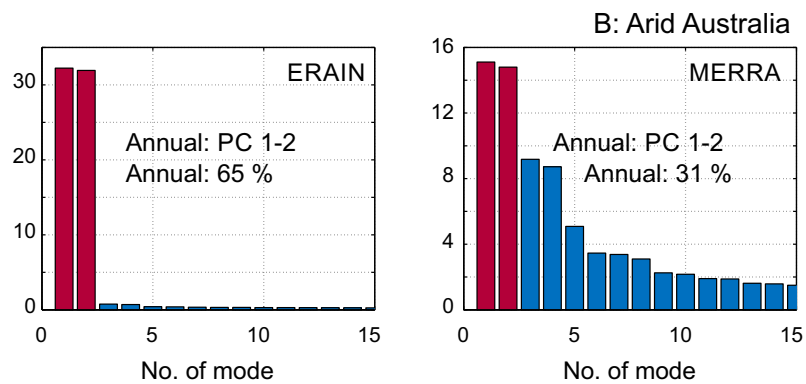
4 Figure 4

Percentage of variance explained by individual modes for environmental loadings for all sections we analysed. The modes which were used to reconstruct the annual changes are marked in red. Also, the percentage of variance explained by annual signal is given in each plot

explains between 60 and $83 \%$ and obviously is location dependent.

For ECCO2 loading model, the 2nd and 3rd PCs from sections: A: Equatorial South America, C: Warm North America, D: Snow Asia, and D: Snow North America are related to the common annual signal, while for 3 sections, namely: B: Arid North America, E: Polar Antarctica and E: Polar North America-the 3rd and 4th. For all these cases, first PCs explain the long-term non-linear trend. As an example, for E: Polar Antarctica section, the ECCO2 series are characterized by large non-linearity mainly between 2006 and 2015, while for stations included in E: Polar North America section, the non-linearity from 2000 onwards is hardly seen, as the variance explained by this non-linear trend is comparable to the annual signal. The long-term trend seen in the $\mathrm{ECCO} 2$ model may result from the Boussinesq approximation used to create this model (Ponte et al. 2007). For remaining 9 sections, annual signals were detected in the 1st and 2nd PCs with the amount of variance explained by annual curve being significantly higher than the variance explained by other modes.

Figure 5 presents the spatial distribution of the percentage of variance which is explained by a common annual signal in the vertical direction for ECCO2, ERAIN and MERRA model, respectively, for individual stations situated in different sections.

For the non-tidal ocean loading model, the common annual signal identified using MSSA accounts for an average of $16 \%$ of the total variance of data. The highest contribution of the annual signal was noticed for stations situated in A: Equatorial Australia section, reaching 34\%. In Europe, the annual signal explains approximately $26 \%$, while in North and South Americas 6 and 9\%, respectively. Common annual oscillations identified using MSSA for atmospheric loading account for an average of $24 \%$ of the total variance of data with the highest percentage equal to 80,72 and $74 \%$, respectively, for stations situated in South Asia, in North Australia and in Asia. The percentage of variance related to annual oscillation explains approximately $4 \%$ of the total variance for stations in Europe. The annual signal estimated using MSSA approach for the hydrological loading models explains around $68 \%$ of the total variance, proving that local hydrological plays a significant role in the observed signals. We noticed that stations situated in Europe are strongly affected by annual oscillations from hydrological loading, which accounts for $80 \%$. Those results may be further used for other research related for example to the climate studies, but it falls out of the scope of this paper.

Then, we estimated the RCs for ERAIN, MERRA and ECCO2 models for all examined stations. Figure 6 reveals the original MERRA time series for stations from A: Equatorial Asia section and common seasonal signal derived by the MSSA approach. Due to the non-parametric character of MSSA, we were able to estimate common seasonal pattern which is not constant over time. From Fig. 6, we can notice that the maximum amplitude estimated for A: Equatorial Asia was equal to $5.9 \mathrm{~mm}$ at the beginning of 2007, while the smallest peak was equal to $4.8 \mathrm{~mm}$ in 2002 . We compared the common annual signals estimated with MSSA with those determined with LSE separately for each loading model, obtaining maximum difference in peak-topeak oscillations of $2.2 \mathrm{~mm}$ (or $77 \%$ in other words) at maximum.

Finally, the common seasonal signal estimated from ERAIN, MERRA, and ECCO2 with MSSA algorithm was subtracted from the GPS height time series. Due to numerical artefacts, the environmental loadings do not account for entire seasonal oscillation observed by the GPS time series, as pointed the Introduction section. Therefore, we modelled the remaining annual oscillations from the residual time series using the LSE approach. The median amplitude of the residual annual oscillations estimated for the 229 GPS stations was equal to $1.7 \mathrm{~mm}$. They arose from the fact that the common annual oscillation estimated with MSSA did not reflect the entire seasonal changeability of series due to its spatial pattern. These residual annual oscillations were 


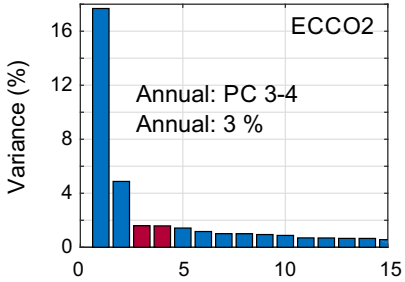

No. of mode
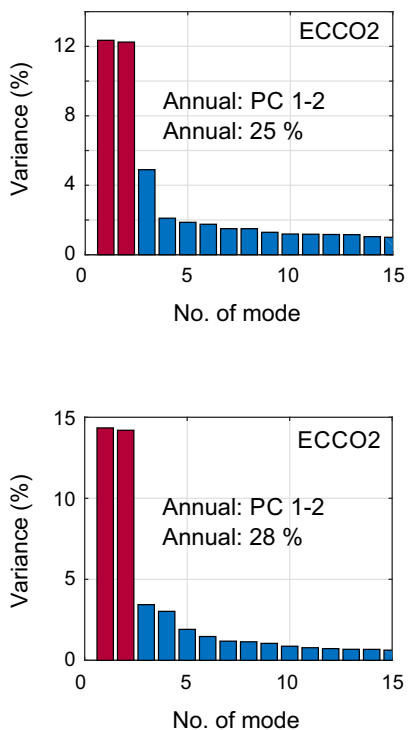

No. of mode

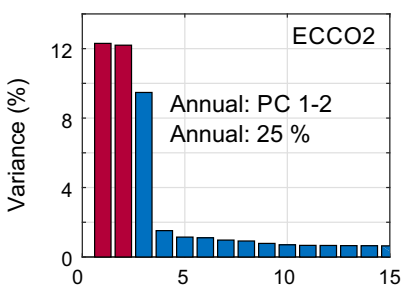

No. of mode

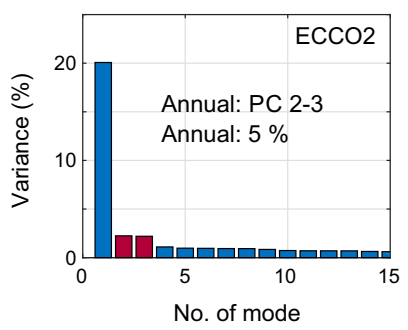

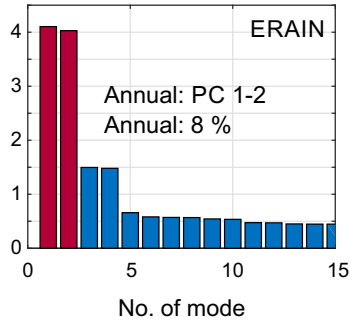
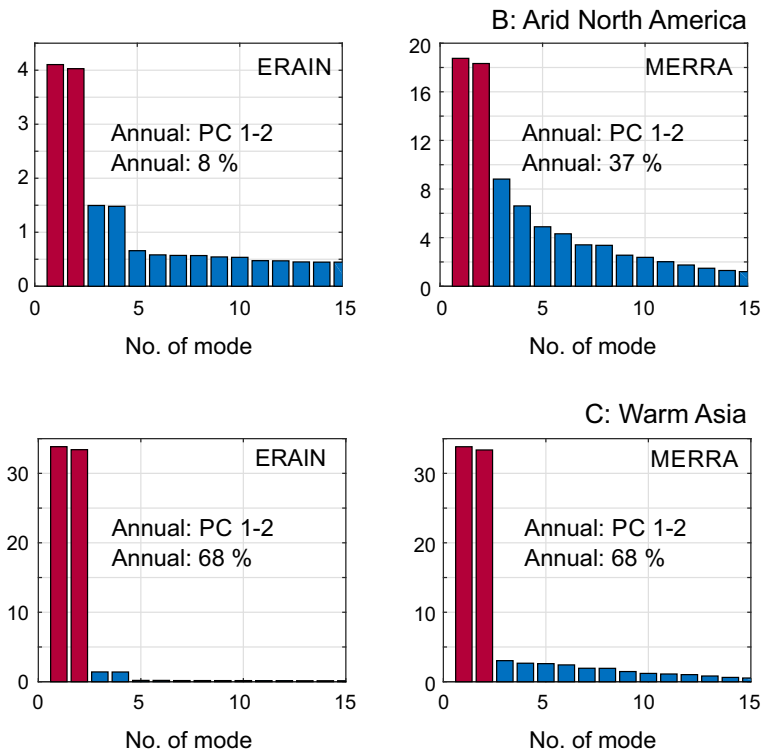

C: Warm Asia

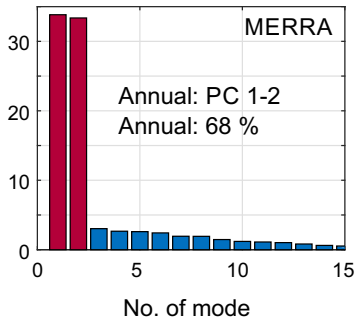

C: Warm Australia

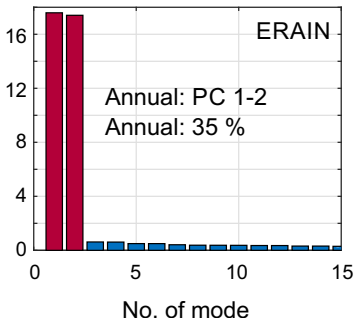

No. of mode

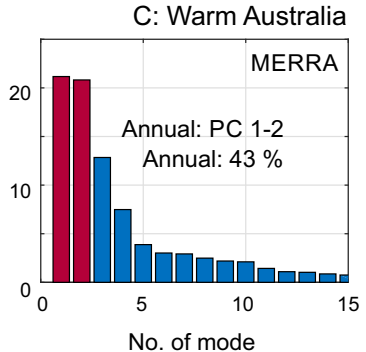

C: Warm Europe

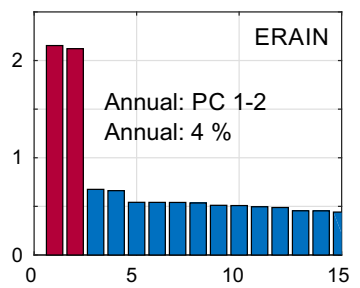

No. of mode

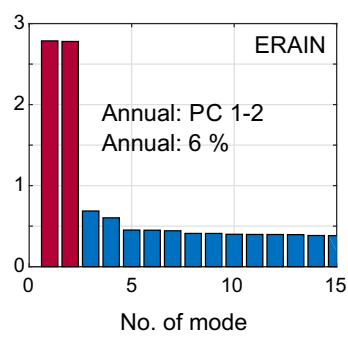

C: Warm North America
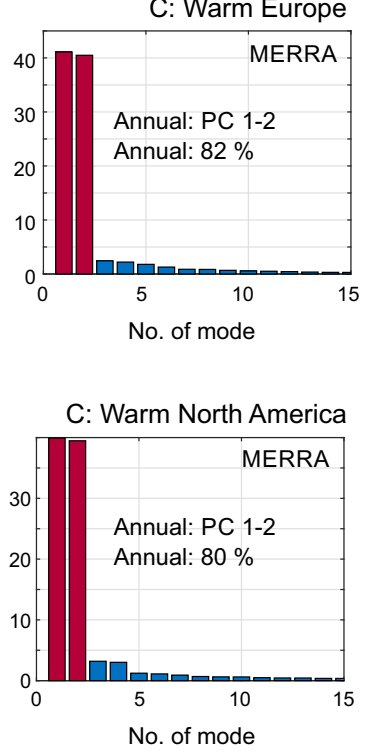

No. of mode

Figure 4

continued 

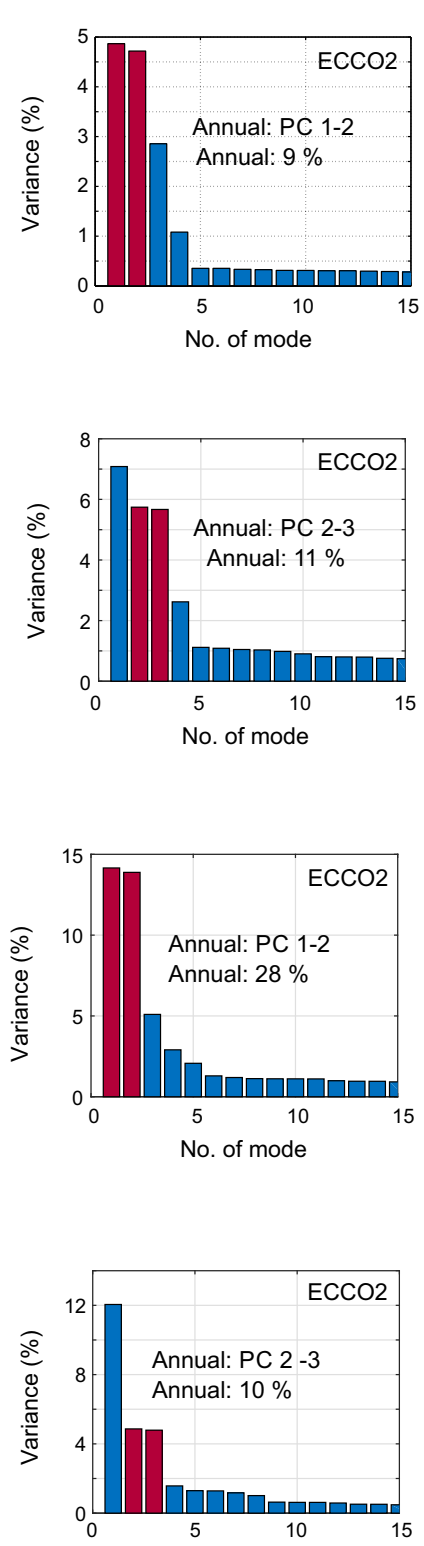

No. of mode

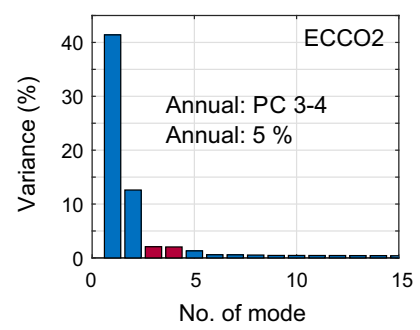

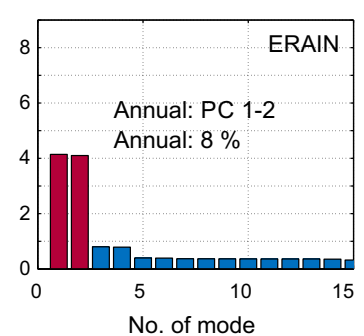

No. of mode
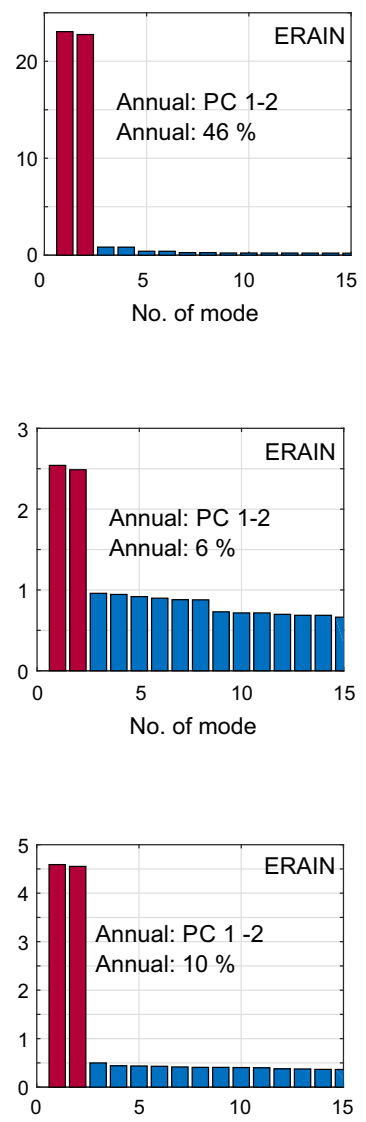

No. of mode

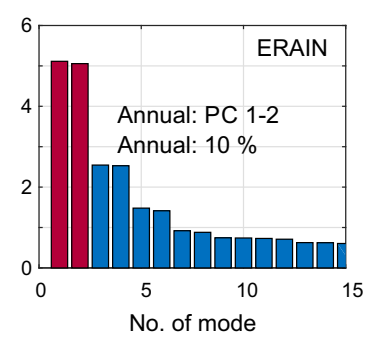

Figure 4

continued

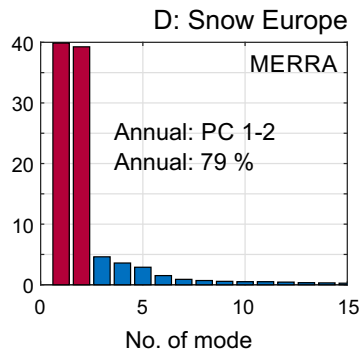

D: Snow North America
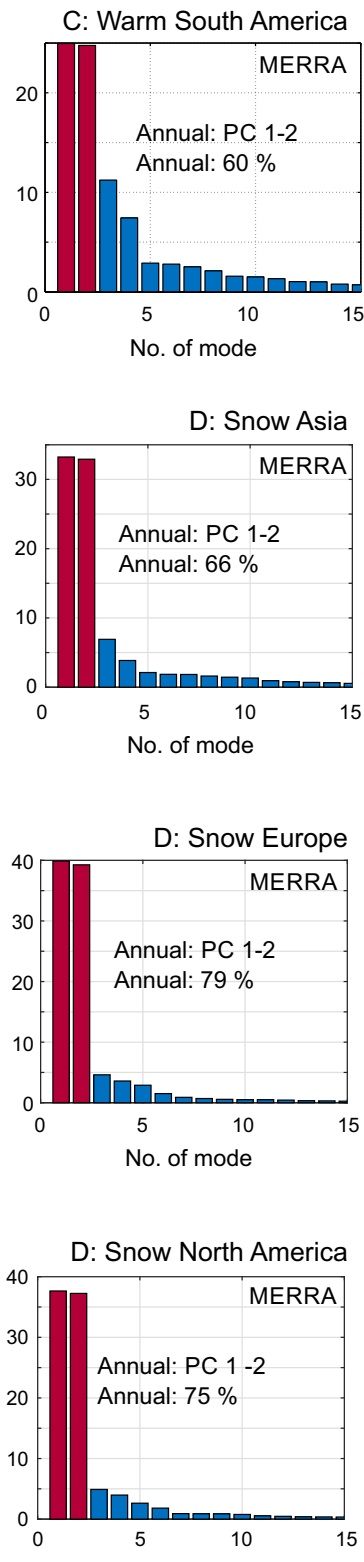

No. of mode

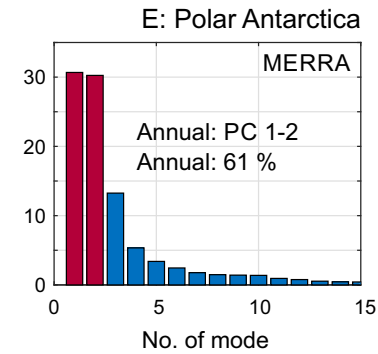



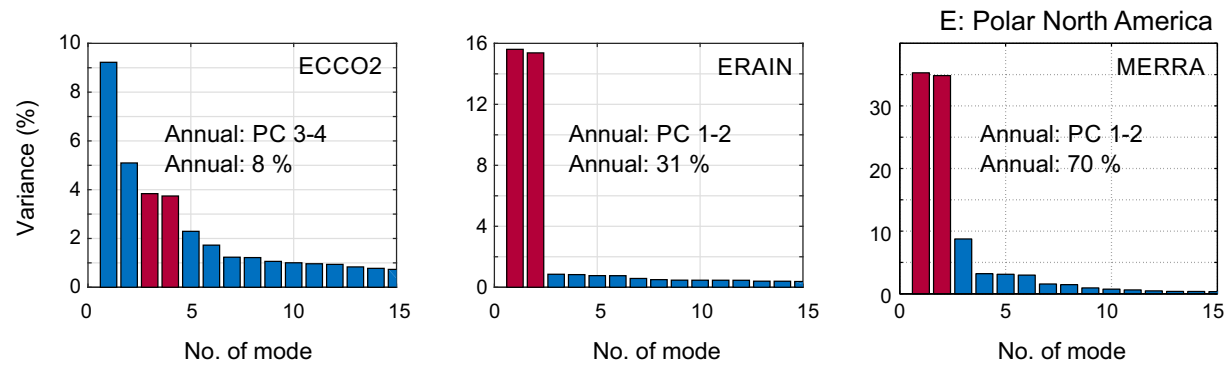

Figure 4

continued

subtracted to estimate the series submitted for further analysis.

\subsection{Common Mode Errors}

In order to show the main advantage of estimating the seasonal signal with MSSA, we determined the Common Mode Error (CME) with the use of the Principal Component Analysis (PCA) for incomplete GNSS time series as proposed by Shen et al. (2013). This procedure was previously successfully applied by the authors for spatio-temporal analysis of the GPS position time series (Bogusz et al. 2015b; Gruszczynski et al. 2016). First, CME was estimated for residuals after MSSA curves were removed. Then, CME was estimated for residuals after direct subtraction of environmental loading models. The second approach is nowadays widely used to remove the environmental effects from the GPS position time series, while first is a novelty introduced in this paper.

Figure 7 presents the selected stacked power spectral densities of height time series CME determined for individual sections after environmental effect was removed using MSSA-derived annual curve as well as removed directly from time series. These results confirm that although the direct subtraction of environmental loading models from the GPS position time series may help in removing the loading effect and in reducing the RMS values, it causes a change in the character of the stochastic part of time series leading to an artificial subtraction of some power in CME. On the other hand, we may suppose that some part of the Common Mode Error observed by the GPS sensors arises from environmental influence. However, it has not yet been considered if the GPS records are sensitive to environmental influence in the frequency bands between 10 and 80 cpy. If not, we should not artificially influence the character of CME by removal of entire environmental loadings.

From Fig. 7, we may notice that the character of CME is very similar for both cases for the B: Arid Australia section. For A: Equatorial Australia, C: Warm South America, D: Snow Europe, and E: Polar North America, we can observe that environmental loading models remove lots of power in a frequency band between 10 and 80 cpy. Especially, zones as C: Warm South America and D: Snow Europe are affected by a large cut in the power, and, therefore, a change in a character of CME. When MSSA curves which reveal the common geophysical signal are removed from the GPS position time series, the change in power is not observed, which means that the character of CME remains intact.

Based on the results, we concluded that the common geophysical signal can be successfully modelled with the MSSA method and then removed from the GPS position time series. We showed that the CME values are not affected by MSSA estimates, which makes it to be an effective approach to investigate and/or subtract a common large-scale environmental effect in the GPS position time series.

\section{Discussion and Conclusions}

The MSSA approach is a non-parametric method that is able to investigate simultaneously the spatial and temporal correlations for analysing the dependence between any geodetic time series. This method 

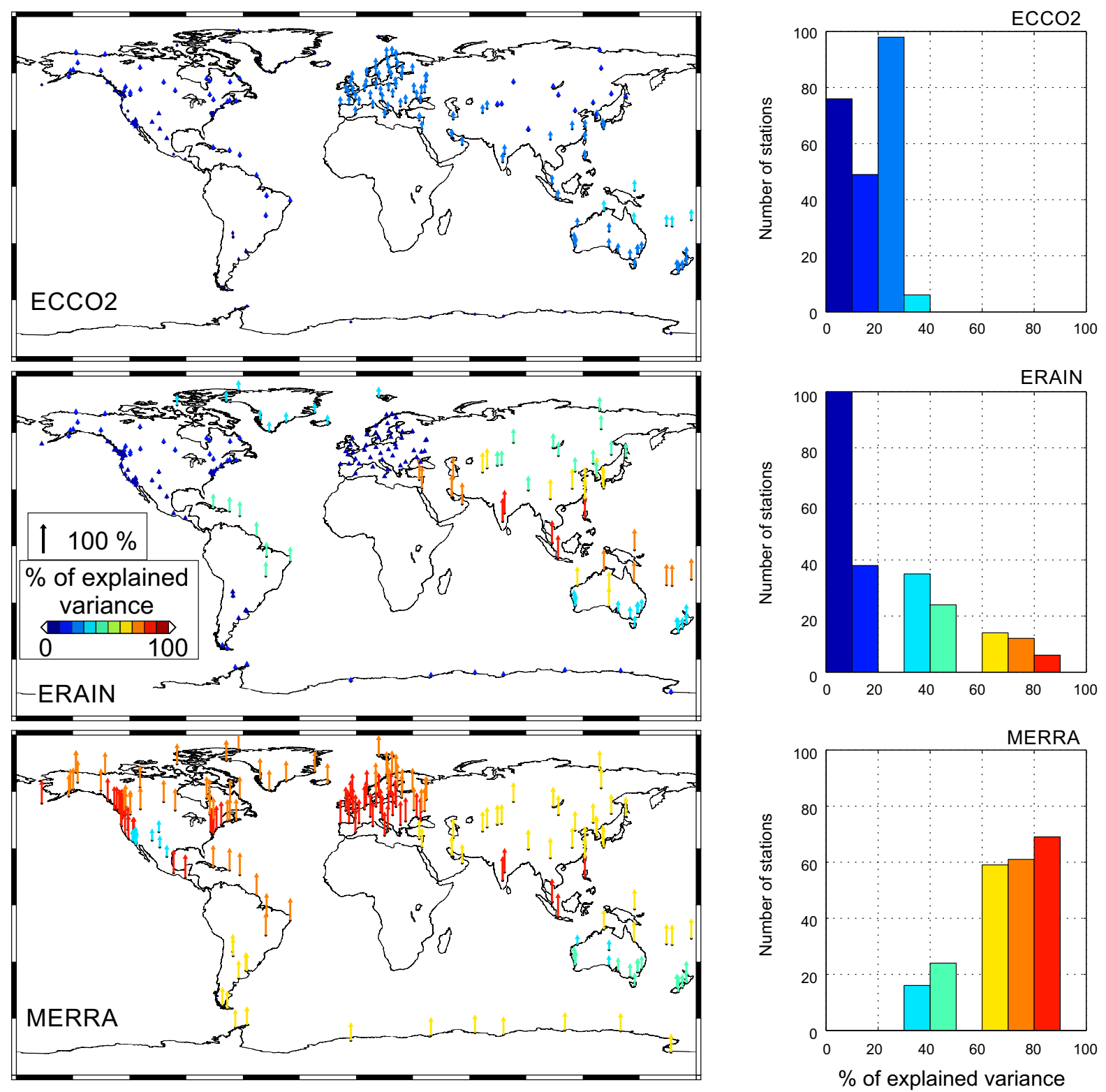

Figure 5

Percentage of variance explained by common annual signal in the vertical component of environmental loadings

provides the opportunity to determine a signal which is common for stations included in the analysis. In this research, we focused on the common annual signal as environmental loadings from atmosphere, hydrosphere and non-tidal ocean can similarly affect stations situated in a specific area. As it has been already proven, the GPS position time series are influenced by real geophysical changes, systematic errors and spurious effects (Dong et al. 2002; Ray et al. 2008; Collilieux et al. 2010), which may be observed as seasonal curves with amplitudes changing over time (Gegout et al. 2010; Bennet 2008; Davis et al. 2012; Chen et al. 2013). If we do not assume the time variability of seasonal variations, this can be transferred to the reliability of station's velocity estimates (Klos et al. 2017).

The recent researches (Santamaría-Gomez and Mémin 2015; $\mathrm{He}$ et al. 2017) confirmed that 


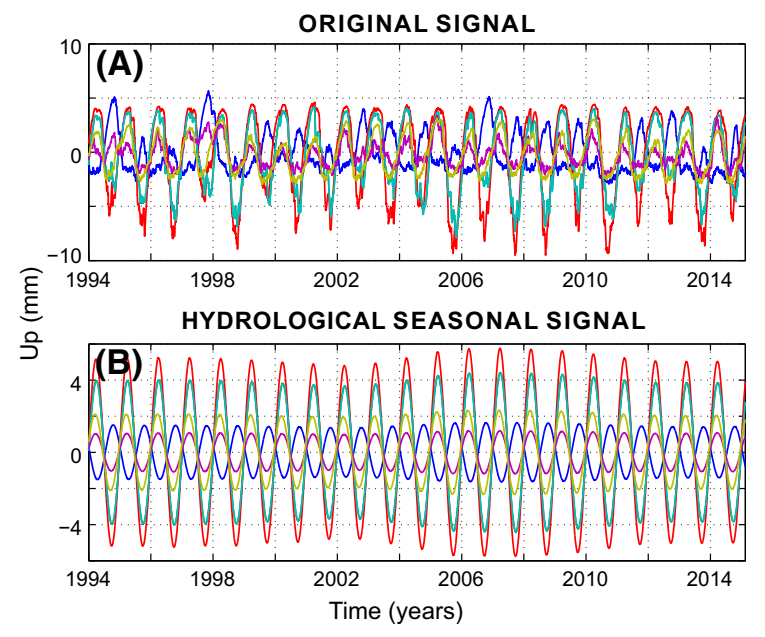

Figure 6

Original height time series a and common annual signal b, estimated from MERRA model for stations included in A:

Equatorial Asia. Different colours denote different time series

environmental loading models should be considered before the velocity of GPS station is estimated from the position time series. Collilieux et al. (2012) used the loading models to mitigate the aliasing effect in the GPS technique during the frame transformation. Klos et al. (2017) proved that a direct removal of loadings causes a reduction in the RMS values, but it also changes the power spectrum of the position time series for frequencies between 4 and 80 cpy, removing a part of the power. Following up, this change in the power spectrum can cause an underestimation of the uncertainty of station's velocity. As we still do not know if GPS senses the environmental effects in the entire frequency range, i.e. we are not sure if the high frequency changes of GPS are due to environmental loadings, we should not remove the environmental effects directly from the GPS position time series. What should be aimed at is the stochastic part which remains intact.

To retrieve the real geophysical changes with no influence on the character of the residual GPS position time series, we proposed to model and subtract the common annual part from environmental loadings. In this way, we remove the geophysical signals of common origin which may affect the changes in the positions of GPS permanent stations. We used a set of the IGS ITRF2014 stations and discussed the amount of variance explained by individual models. Afterwards, the common annual curve was removed from the heights.

We determined the common seasonal pattern for environmental loadings which are not constant over time. For example, for A: Equatorial Asia section we
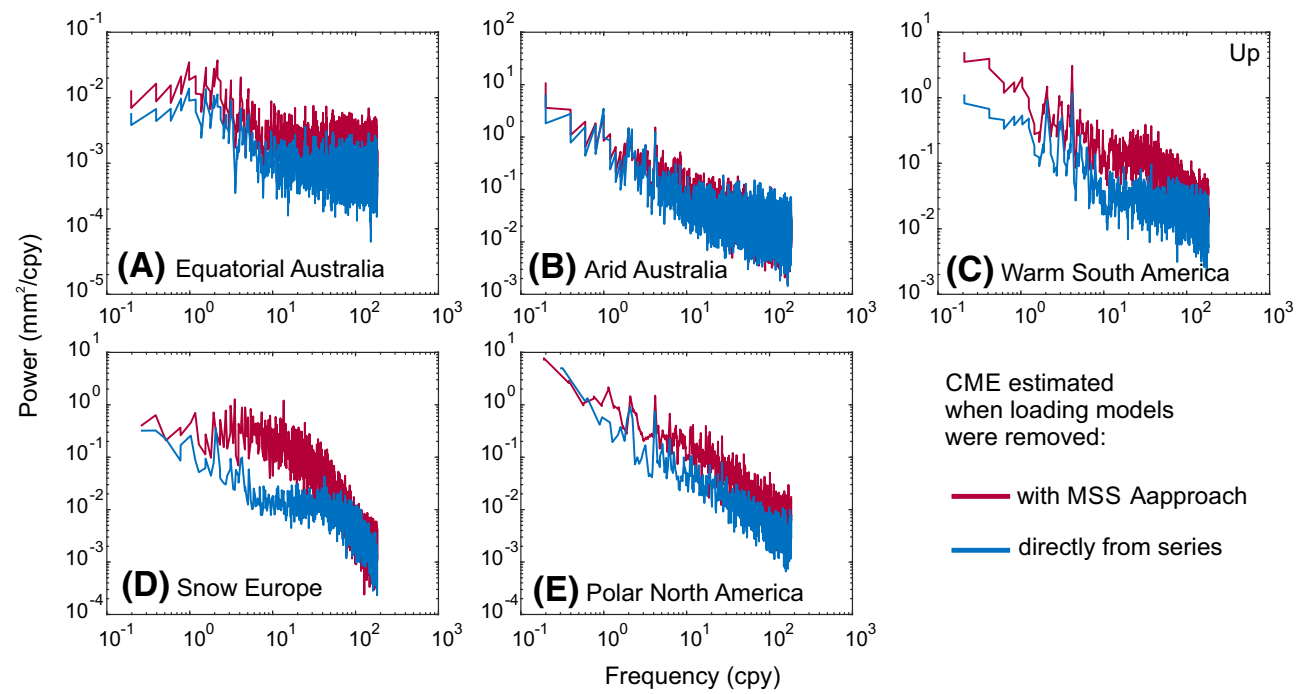

CME estimated when loading models were removed:

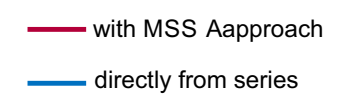

Figure 7

Stacked power spectral densities (PSDs) estimated for CME of residuals of the GPS height time series after the influence of environmental loadings was removed using MSSA curve (in red) and directly from series (in blue). The CME was stacked within each of the considered sections. All PSDs were estimated using Welch periodogram (Welch 1967) 
may make a misfit of $2.2 \mathrm{~mm}$ if we assume the time constancy. Annual signal in the MERRA model accounts for $68 \%$ of the total variance. It proves that hydrological series are strongly affected by common annual signal. For the ERAIN model, the annual curve explains $24 \%$ of the total variance on average, while for the ECCO2 model-only $16 \%$.

The highest contribution of the annual changes into ECCO2 loading model reached $40 \%$ for stations situated in Indonesia. This was previously noticed by van Dam et al. (2012), who emphasized that both the RMS values and maximum predicted radial surface displacement are also much larger for Indonesia than they are for any other regions of the world. Also, the region of North Sea is affected by large contribution of non-tidal ocean loading, as stated before by Williams and Penna (2011). They noticed that the removal of ECCO2 model from the GPS position time series can reduce the variance of the series of the same amount as the atmospheric loading does. In our analysis, we observed that the contribution of annual curve for European stations for ECCO2 is much higher $(40 \%)$ than it is for ERAIN model (10\%).

As was previously noted by van Dam et al. (2012), the most of the power in the non-tidal ocean loading records is at the annual period with other frequencies being not as powerful as annual signal. This was observed in our research as well, as for almost all sections considered, the annual signal explains most of the variance of time series. We also found that most of the power in the ERAIN atmospheric model is cumulated at 1 cpy excluding sections B: Arid North America, C: Warm Europe, D: Snow Europe and E: Polar Antarctica. The annual signal dominates also in the MERRA hydrological model, explaining up to $90 \%$ of the total variance of the height time series.

Van Dam et al. (2012) found the largest reduction in the RMS values for Asian stations after atmospheric non-tidal loading was incorporated. In our analysis, we noticed that Australian, Indonesian and Asian stations are characterized by the largest contribution of annual signal in the total variance of ERAIN model. If the correlation between the GPS height time series and ERAIN model is high, as showed by van Dam et al. (2012), we expect that the annual curves will constitute a good approximation of annual signal found in the GPS position time series. For MERRA model, we compared our results with Tregoning et al. (2009), who found a large RMS reduction of the GPS height time series, when these were corrected for elastic deformation using continental water load estimates derived from GRACE. We found that the percentage of variance explained by annual signal correlates well with the RMS reduction they presented, especially for areas of North America, South America and Northern Australia. For those areas, the reduction in RMS they found varied from -9 to $-3 \mathrm{~mm}$, while the percentage of variance explained by common annual signal we estimated varies between 30 and 50\%. The RMS reduction for stations situated in Central and Southern Europe reached the values between 3 and $9 \mathrm{~mm}$ as reported by Tregoning et al. (2009). For these stations, the percentage of variance we explained by common annual signal is in the range of $80-90 \%$. The above result means that the reduction in RMS values which was found before can arise from the annual signal present in hydrological signal, which dominates the loading effect.

We found the evident long-term trends for ECCO2 model, confirming the findings of van Dam et al. (2012). This trend explains the majority of variance of ECCO2 model for most of sections considered. According to Ponte et al. (2007), the longterm trends in the ECCO2 model may arise from the Boussinesq approximation which is employed to compute the model. Van Dam et al. (2012) emphasized that a real long-term trend in non-tidal ocean loading can arise from a trend in freshwater fluxes, trends in the atmospheric forcing as well as long-term climate variability.

After the common annual seasonal curve was modelled with MSSA and removed from the GPS position time series, the residual station-specific annual curve was removed with LSE, as it may affect the character of stochastic part of the GPS data (Bos et al. 2010; Bogusz and Klos 2016; Klos et al. 2018b). We showed that the amplitudes of residual oscillations do not exceed $2 \mathrm{~mm}$ at maximum. These findings were consistent with results obtained by Klos et al. (2017). In their paper, the authors analysed the residual annual oscillation after the SSA curve was modelled for environmental loading models and then removed from the GPS position time 
series, but on a station-by-station basis. This means that those models underestimate the seasonalities observed by the GPS system. So, probably, the remaining part of signal being present in the seasonal frequency bands arises from the systematic errors which are not of geophysical origin.

The approach based on removing the common environmental effect with the MSSA method we introduced was compared to the widely applied removing the loading models directly from the GPS position time series. The advantages were shown using the CME estimates. When a common annual signal was removed from the GPS position time series, neither removal of power nor artificial reduction in the CME was noticed. In this way, we remove the geophysical annual effects that disturb stations included in a particular section with no influence on the high frequency part of the spectra. We observed that direct subtraction of environmental loading models causes an evident change in the PSD for frequencies between 10 and 80 cpy. Removing the MSSA-derived curves from environmental loading models causes no influence on the stochastic part of the GPS time series. So, a change in the noise character and CME estimates noted before by Yuan et al. (2008), when the environmental loading models were removed directly from series, arose from the artificial cut in the power of residuals of the GPS position time series.

The two-step solution we propose allows us to consider the real geophysical effects arising from environmental loading models and to model the timevarying common seasonal signal using the MSSA approach with no artificial change of the stochastic part of the GPS height time series we analysed. However, this approach can be successfully applied for any other type of geodetic observations, in which we may expect a common influence of different type.

\section{Acknowledgements}

We would like to thank Giuliana Rossi and other anonymous reviewer for their suggestions and comments improving the manuscript. This research was financed by the National Science Centre, Poland, Grant no. UMO-2017/25/B/ST10/02818 under the leadership of Prof. Janusz Bogusz. World Map of Köppen-Geiger Climate Classification was downloaded from http://koeppen-geiger.vu-wien.ac. at/shifts.htm. GPS time series were accessed from http://acc.igs.org/reprocess2.html on 2016-05-05. Environmental loadings were downloaded from EOST loading service: http://loading.u-strasbg.fr/ on 2017-01-10. Maps were drawn in the generic mapping tool (GMT) (Wessel et al. 2013). We modified Matlab-based algorithms written by Eric Breitenberger which were downloaded from https:// pantherfile.uwm.edu/kravtsov/www/downloads/

KWCT2014/SSAMATLAB/mssa/. This research was partially supported by the PL-Grid Infrastructure, grant name "mssagnss".

Open Access This article is distributed under the terms of the Creative Commons Attribution 4.0 International License (http:// creativecommons.org/licenses/by/4.0/), which permits unrestricted use, distribution, and reproduction in any medium, provided you give appropriate credit to the original author(s) and the source, provide a link to the Creative Commons license, and indicate if changes were made.

\section{REFERENCES}

Allen, M. R., \& Robertson, A. W. (1996). Distinguishing modulated oscillations from coloured noise in multivariate datasets. Climate Dynamics, 12, 772-786. https://doi.org/10.1007/ s003820050142.

Altamimi, Z., Rebischung, P., Métivier, L., \& Collilieux, X. (2016). ITRF2014: A new release of the international terrestrial reference frame modelling nonlinear station motions. Journal of Geophysical Research: Solid Earth, 121(8), 6109-6131. https:// doi.org/10.1002/2016JB013098.

Bennet, R. A. (2008). Instantaneous deformation from continuous GPS: Contributions from quasi-periodic loads. Geophysical Journal International, 174(3), 1052-1064. https://doi.org/10. 1111/j.1365-246X.2008.03846.x.

Blewitt, G., \& Lavallée, D. (2002). Effect of annual signals on geodetic velocity. Journal of Geophysical Research, 107(B7), ETG 9-1-ETG 9-11. https://doi.org/10.1029/2001jb000570.

Bogusz, J., Gruszczynska, M., Klos, A., \& Gruszczynski, M. (2015a). Non-parametric estimation of seasonal variations in GPS-derived time series. In: van Dam T. (Eds.) REFAG 2014. International Association of Geodesy Symposia, 146. Cham: Springer. https://doi.org/10.1007/1345_2015_191

Bogusz, J., Gruszczynski, M., Figurski, M., \& Klos, A. (2015b). Spatio-temporal filtering for determination of common mode error in regional GNSS networks. Open Geosciences, 7(1), 140-148. https://doi.org/10.1515/geo-2015-0021.

Bogusz, J., \& Klos, A. (2016). On the significance of periodic signals in noise analysis of GPS station coordinates time series. GPS Solutions, 20(4), 655-664. https://doi.org/10.1007/s10291015-0478-9. 
Bogusz, J., \& Kontny, B. (2011). Estimation of sub-diurnal noise level in GPS time series. Acta Geodynamica et Geomaterialia, 8(3), 273-281.

Bos, M. S., Bastos, L., \& Fernandes, R. M. S. (2010). The influence of seasonal signals on the estimation of the tectonic motion in short continuous GPS time-series. Journal of Geodynamics, 49(3-4), 205-209. https://doi.org/10.1016/j.jog.2009.10.005.

Broomhead, D.S., \& King G.P. (1986a). On the qualitative analysis of experimental dynamical systems. In Adam Hilger (Ed.) Nonlinear Phenomena and Chaos, 113-144. Bristol.

Broomhead, D. S., \& King, G. P. (1986b). Extracting qualitative dynamics from experimental data. Physica, 20(2-3), 217-236. https://doi.org/10.1016/0167-2789(86)90031-X.

Chen, Q., van Dam, T., Sneeuw, N., Collilieux, X., Weigelt, M., \& Rebischung, P. (2013). Singular spectrum analysis for modelling seasonal signals from GPS time series. Journal of Geodynamics, 72, 25-35. https://doi.org/10.1016/j.jog.2013.05.005.

Collilieux, X., Altamimi, Z., Coulot, D., Ray, J., \& Sillard, P. (2007). Comparison of very long baseline interferometry, GPS, and satellite laser ranging height residuals from ITRF2005 using spectral and correlation methods. Journal of Geophysical Research. https://doi.org/10.1029/2007JB004933.

Collilieux, X., Altamimi, Z., Coulot, D., van Dam, T., \& Ray, J. (2010). Impact of loading effects on determination of the International Terrestrial Reference Frame. Advances in Space Research, 45(1), 144-154. https://doi.org/10.1016/j.asr.2009.08. 024.

Collilieux, X., van Dam, T., Ray, J., Coulot, D., Métivier, L., \& Altamimi, Z. (2012). Strategies to mitigate aliasing of loading signals while estimating GPS frame parameters. Journal of Geodesy, 86(1), 1-14. https://doi.org/10.1007/s00190-011-0487-6.

Dach, R., Boehm, J., Lutz, S., Steigenberger, P., \& Beutler, G. (2011). Evaluation of the impact of atmospheric pressure loading modelling on GNSS data analysis. Journal of Geodesy, 85(2), 75-91. https://doi.org/10.1007/s00190-010-0417-z.

Davis, J. L., Wernicke, B. P., \& Tamisiea, M. E. (2012). On seasonal signals in geodetic time series. Journal of Geophysical Research. https://doi.org/10.1029/2011JB008690.

Dee, D. P., Uppala, S. M., Simmons, A. J., Berrisford, P., Poli, P., Kobayashi, S., et al. (2011). The ERA-Interim reanalysis: configuration and performance of the data assimilation system. Quarterly Journal of the Royal Meteorological Society, 137(656), 553-597. https://doi.org/10.1002/qj.828.

Didova, O., Gunter, B., Riva, R., Klees, R., \& Roese-Koerner, L. (2016). An approach for estimating time-variable rates from geodetic time series. Journal of Geodesy, 90(11), 1207-1221. https://doi.org/10.1007/s00190-016-0918-5.

Dong, D., Fang, P., Bock, Y., Cheng, M. K., \& Miyazaki, S. (2002). Anatomy of apparent seasonal variations from GPSderived site position time series. Journal of Geophysical Research, 107(4), ETG 9-1-ETG 9-16. https://doi.org/10.1029/ $2001 \mathrm{jb} 000573$.

Dong, D., Fang, P., Bock, Y., Webb, F., Prawirodirdjo, L., Kedar, S., et al. (2006). Spatio-temporal filtering using principal component analysis and Karhunen-Loeve expansion approaches for regional GPS network analysis. Journal of Geophysical Research. https://doi.org/10.1029/2005JB003806.

Freymueller, J.T. (2009). Seasonal position variations and regional Reference frame realization. In H. Drewes (Ed.), Geodetic Reference Frames, International Association of Geodesy Symposia,
134, 191-196. Springer, Berlin. https://doi.org/10.1007/978-3642-00860-3_30.

Gegout, P., Boy, J.-P., Hinderer, J., \& Ferhat, G. (2010). Modeling and observation of loading contribution to time-variable GPS site positions. In S. Mertikas (Ed.), Gravity, Geoid and Earth Observation, International Association of Geodesy Symposia, 135, 651-659. Springer, Berlin. https://doi.org/10.1007/978-3642-10634-7_86.

Ghil, M., Allen, M. R., Dettinger, M. D., Ide, K., Kondrashov, D., Mann, M. E., et al. (2002). Advanced spectral methods for climatic time series. Reviews of Geophysics. https://doi.org/10. 1029/2000RG000092.

Gruszczynska, M., Klos, A., Gruszczynski, M., \& Bogusz, J. (2016). Investigation of time-changeable seasonal components in the GPS height time series: A case study for Central Europe. Acta Geodynamica et Geomaterialia, 13(3), 281-289. https://doi.org/ 10.13168/AGG.2016.0010.

Gruszczynska, M., Klos, A., Rosat, S., \& Bogusz, J. (2017). Deriving common seasonal signals in GPS position time series: By using multichannel singular spectrum analysis. Acta Geodynamica et Geomaterialia, 14(3), 267-278. https://doi.org/10. 13168/AGG.2017.0010.

Gruszczynski, M., Klos, A., \& Bogusz, J. (2016). Orthogonal transformation in extracting of common mode errors from continuous GPS networks. Acta Geodynamica et Geomaterialia, 13(3), 291-298. https://doi.org/10.13168/AGG.2016.0011.

He, X., Montillet, J.-P., Hua, X., Yu, K., Jiang, W., \& Zhou, F. (2017). Noise analysis for environmental loading effect on GPS time series. Acta Geodynamica et Geomaterialia, 14(1), 131-142. https://doi.org/10.13168/AGG.2016.0034.

Jiang, W., Li, Z., van Dam, T., \& Ding, W. (2013). Comparative analysis of different environmental loading methods and their impacts on the GPS height time series. Journal of Geodesy, 87(7), 687-703. https://doi.org/10.1007/s00190-013-0642-3.

King, M., Altamimi, Z., Boehm, J., Bos, M., Dach, R., Elosegui, P., Fund, F., Hernández-Pajares, M., Lavallee, D., Mendes Cerveira, P. J., Penna, N., Riva, R. E. M., Steigenberger, P., van Dam, T., Vittuari, L., Williams, S., Willis, P. (2010). Improved constraints on models of glacial isostatic adjustment: a review of the contribution of ground-based geodetic observations. Surveys in Geophysics, 31(5), 465-507. https://doi.org/10.1007/s10712-010-9100-4.

Klos, A., \& Bogusz, J. (2017). An evaluation of velocity estimates with a correlated noise: case study of IGS ITRF2014 European stations. Acta Geodynamica et Geomaterialia, 14(3), 255-265. https://doi.org/10.13168/AGG.2017.0009.

Klos, A., Bogusz, J., Figurski, M., \& Gruszczynski, M. (2016). Error analysis for European IGS stations. Studia Geophysica et Geodaetica, 60(1), 17-34. https://doi.org/10.1007/s11200-015-0828-7.

Klos, A., Bos, M. S., \& Bogusz, J. (2018a). Detecting time-varying seasonal signal in GPS position time series with different noise levels. GPS Solutions. https://doi.org/10.1007/s10291-017-0686-6.

Klos, A., Gruszczynska, M., Bos, M. S., Boy, J.-P., \& Bogusz, J. (2017). Estimates of vertical velocity errors for IGS ITRF2014 stations by applying the improved singular spectrum analysis method and environmental loading models. Pure and Applied Geophysics. https://doi.org/10.1007/s00024-017-1494-1.

Klos, A., Olivares, G., Teferle, F. N., Hunegnaw, A., \& Bogusz, J. (2018b). On the combined effect of periodic signals and colored noise on velocity uncertainties. GPS Solutions. https://doi.org/10. 1007/s10291-017-0674-x. 
Márquez-Azúa, B., \& DeMets, C. (2003). Crustal velocity field of Mexico from continuous GPS measurements, 1993 to June 2001: Implications for the neotectonics of Mexico. Journal of Geophysical Research. https://doi.org/10.1029/2002JB002241.

Menemenlis, D., Campin, J., Heimbach, P., Hill, C., Lee, T., Nguyen, A., et al. (2008). ECCO2: High resolution global ocean and sea ice data synthesis. Mercator Ocean Quarterly Newsletter, 31, 13-21.

Nikolaidis, R. (2002). Observation of geodetic and seismic deformation with the Global Positioning System. Ph.D. thesis. Univ. of Calif., San Diego

Penna, N. T., King, M. A., \& Stewart, M. P. (2007). GPS height time series: Short-period origins of spurious long-period signals. Journal of Geophysical Research. https://doi.org/10.1029/2005JB004047.

Plaut, G., \& Vautard, R. (1994). Spells of low-frequency oscillations and weather regimes in the northern hemisphere. Journal of the Atmospheric Sciences, 51(2), 210-236. https://doi.org/10. 1175/1520-0469(1994)051<0210:SOLFOA>2.0.CO;2.

Ponte, R., Quinn, K., Wunsch, C., \& Heimbach, P. (2007). A comparison of model and GRACE estimates of the large-scale seasonal cycle in ocean bottom pressure. Geophysical Research Letters. https://doi.org/10.1029/2007GL029599.

Ray, J., Altamimi, Z., Collilieux, X., \& van Dam, T. (2008). Anomalous harmonics in the spectra of GPS position estimates. GPS Solutions, 12(1), 55-64. https://doi.org/10.1007/s10291-007-0067-7.

Rebischung, P., Altamimi, Z., Ray, J., \& Garayt, B. (2016). The IGS contribution to ITRF2014. Journal of Geodesy, 90(7), 611-630. https://doi.org/10.1007/s00190-016-0897-6.

Reichle, R. H., Koster, R. D., De Lannoy, G. J. M., Forman, B. A., Liu, Q., Mahanama, S. P. P., et al. (2011). Assessment and enhancement of MERRA land surface hydrology estimates. Journal of Climate, 24, 6322-6338. https://doi.org/10.1175/ JCLI-D-10-05033.1.

Rubel, F., \& Kottek, M. (2010). Observed and projected climate shifts 1901-2100 depicted by world maps of the Köppen-Geiger climate classification. Meteorologische Zeitschrift, 19, 135-141. https://doi.org/10.1127/0941-2948/2010/0430.

Santamaría-Gomez, A., Bouin, M.-N., Collilieux, X., \& Woppelmann, G. (2011). Correlated errors in GPS position time series: Implications for velocity estimates. Journal of Geophysical Research. https://doi.org/10.1029/2010JB007701.

Santamaría-Gomez, A., \& Mémin, A. (2015). Geodetic secular velocity errors due to interannual surface loading deformation. Geophysical Journal International, 202, 763-767. https://doi. org/10.1093/gji/ggv190.

Shen, Y., Li, W., Xu, G., \& Li, B. (2013). Spatio-temporal filtering of regional GNSS network's position time series with missing data using principle component analysis. Journal of Geodesy. https://doi.org/10.1007/s00190-013-0663-y.

Shen, Y., Peng, F., \& Li, B. (2015). Improved singular spectrum analysis for time series with missing data. Nonlinear Processes in Geophysics, 22, 371-376. https://doi.org/10.5194/npg-22-371-2015.

Tesmer, V., Steigenberger, P., Rothacher, M., Boehm, J., \& Meisel, B. (2009). Annual deformation signals from homogeneously reprocessed VLBI and GPS height time series. Journal of
Geodesy, 83(10), 973-988. https://doi.org/10.1007/s00190-0090316-3.

Tregoning, P., Watson, C., Ramillien, G., McQueen, H., \& Zhang, J. (2009). Detecting hydrologic deformation using GRACE and GPS. Geophysical Research Letters. https://doi.org/10.1029/ 2009GL038718.

van Dam, T., Collilieux, X., Wuite, J., Altamimi, Z., \& Ray, J. (2012). Nontidal ocean loading: Amplitudes and potential effects in GPS height time series. Journal of Geodesy, 86(11), 1043-1057. https://doi.org/10.1007/s00190-012-0564-5.

van Dam, T., \& Wahr, J. M. (1987). Displacements of the Earth's surface due to atmospheric loading: Effects on gravity and baseline measurements. Journal of Geophysical Research: Solid Earth, 92(B2), 1281-1286. https://doi.org/10.1029/JB092iB02p01281.

van Dam, T., \& Wahr, J. M. (1998). Modeling environmental loading effects: A review. Physics and Chemistry of the Earth, 23, 1077-1086.

van Dam, T., Wahr, J., Milly, P. C. D., Shmakin, A. B., Blewitt, G., Lavallée, D., et al. (2001). Crustal displacements due to continental water loading. Geophysical Research Letters, 28(4), 651-654. https://doi.org/10.1029/2000GL012120.

Walwer, D., Calais, E., \& Ghil, M. (2016). Data-adaptive detection of transient deformation in geodetic networks. Journal of Geophysical Research: Solid Earth, 121(3), 2129-2152. https://doi. org/10.1002/2015JB012424.

Wdowinski, S., Bock, Y., Zhang, J., Fang, P., \& Genrich, J. (1997). Southern California permanent GPS geodetic array: Spatial filtering of daily positions for estimating coseismic and postseismic displacements induced by the 1992 Landers earthquake. Journal of Geophysical Research, 102(B8), 18057-18070. https://doi.org/ 10.1029/97JB01378.

Welch, P. D. (1967). The use of fast fourier transform for the estimation of power spectra: A method based on time averaging over short. Modified Periodograms, IEEE Transactions on Audio Electroacoustics, 15, 70-73. https://doi.org/10.1109/TAU.1967.1161901.

Wessel, P., Smith, W. H. F., Scharroo, R., Luis, J., \& Wobbe, F. (2013). Generic mapping tools: Improved version released. Eos, Transactions, American Geophysical Union, 94(45), 409-410. https://doi.org/10.1002/2013EO450001.

Williams, S. D. P. (2003). The effect of coloured noise on the uncertainties of rates estimated from geodetic time series. Journal of Geodesy, 76(9-10), 483-494. https://doi.org/10.1007/ s00190-002-0283-4.

Williams, S. D. P., \& Penna, N. T. (2011). Non-tidal ocean loading effects on geodetic GPS heights. Geophysical Research Letters, 38, L09314. https://doi.org/10.1029/2011GL046940.

Yuan, L., Ding, X., Chen, W., Guo, Z., Chen, S., Hong, B., et al. (2008). Characteristics of daily position time series from the Hong Kong GPS fiducial network. Chinese Journal of Geophysics, 51(5), 1372-1384. https://doi.org/10.1002/cjg2.1292.

Zhu, C., Lu, Y., Shi, H., \& Zhang, Z. (2016). Spatial and temporal patterns of the inter-annual oscillations of glacier mass over Central Asia inferred from Gravity Recovery and Climate Experiment (GRACE) data. Journal of Arid Land, 9(1), 87-97. https://doi.org/10.1007/s40333-016-0021-z.

(Received November 2, 2017, revised January 30, 2018, accepted February 21, 2018, Published online March 3, 2018) 